\title{
Experimental Research on the Performance of UHMWPE Fiber Reinforced Concrete Multiply Impacted by Bullets
}

\author{
Mohan $\mathrm{Xu}^{1, \mathrm{a}}$, Luhui Yan ${ }^{1, \mathrm{~b}}$, Qiaoheng Liang ${ }^{2, \mathrm{c}}$ and Shuaishuai Wang ${ }^{1, \mathrm{~d}}$ \\ ${ }^{1}$ National University of Defense Technology, Changsha 410072, China; \\ 2 Special Police College, Beijing 102200, China. \\ axmh19419@163.com, byan_Ihh@aliyun.com, 'Iqhafx@163.com, dtzwwss@163.com
}

Keywords: UHMWPE fiber reinforced concrete; multiple impacts; experimental research; antipenetration performance.

\begin{abstract}
Based on the engineering projection against multiple impacts, the test of anti-multiple impacts was carried out towards UHMWPE fiber reinforced concrete, in which five kinds of fiber volume fraction $(0 \%, 0.3 \%, 0.5 \%, 0.7 \% 1.0 \%)$ were designed. The damage patterns were analyzed and the penetration depth was fitted by empirical formula. Excellent effect of UHMWPE fiber reinforced concrete for reducing the damage under multiple impacts was studied. Appropriate fiber volume fraction can effectively improve the anti-penetration performance of concrete. When the fiber volume fraction was between $0.3 \%$ and $0.5 \%$, the improvement was the most remarkable.
\end{abstract}

\section{Introduction}

Concrete is the most commonly used building materials for the projection whose anti-penetration performance has been a hot topic in the defense and military fields. The research of fiber reinforced concrete has been rapid increasing in order to improve the strength and toughness of concrete ${ }^{[1,2,3]}$. Many researchers have studied the anti-penetration properties of different kinds of fiber reinforced concrete under the single impact. The results ${ }^{[4,5]}$ show that mixing fiber into concrete can remarkably improve the anti-impact performance of concrete.

In the actual conditions, the concrete structure may be subject to multiple impacts. The anti-impact performance of concrete structure will be affected under the superposition of the penetration. Therefore researches of concrete multiply impacted have been carried out. Gomez.J.T ${ }^{\text {[7] }}$ studied multiple impacts towards targets under semi-infinite conditions and proposed empirical equation of penetration depth applied to multiple impacts. Lai ${ }^{[8]}$ designed a multiple-impacts test for ultra-high performance concrete and improved the empirical formula. Jiang ${ }^{[9]}$ taked the effect of the eccentricity of the bullet holes into consideration in the multiple impacts test of steel tube concrete.

UHMWPE ( Ultra-high-molecular-weight polyethylene) fiber is a flexible fiber with very high strength, which has been widely used in body armor. Relevant researches ${ }^{[10,11,12]}$ show that UHMWPE can well improve the tensile strength of concrete, which dramatically increases antidamage properties under the impacts of bullets. Anti-multiple impacts tests of UHMWPE reinforced concrete were carried out in this paper in order to further evaluate the properties of this material. The influence of fiber volume fraction on the anti-impact properties of concrete under multiple impacts was studied.

\section{Systems and Methods of Tests}

\subsection{Test system.}

The test system consists of a transmitter, a speed measuring device and a target, as shown in Fig.1. The test used $12.7 \mathrm{~mm}$ Hulling penetrator, as shown in Fig.2, where the projectile weight $47.3 \sim 49.0 \mathrm{~g}$, length $59.4 \mathrm{~mm}$, diameter $12.7 \mathrm{~mm}$; The Tungsten core weights $19.7 \mathrm{~g}$, length $34.2 \mathrm{~mm}$, and diameter $7.5 \mathrm{~mm}$. 


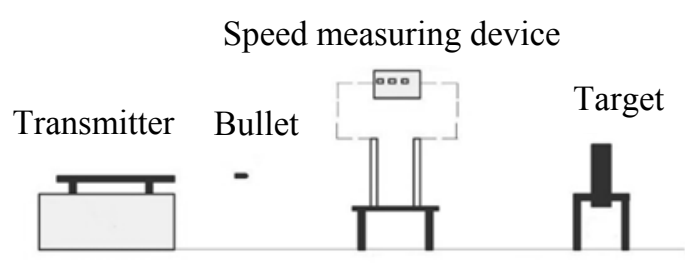

Fig.1 Test system

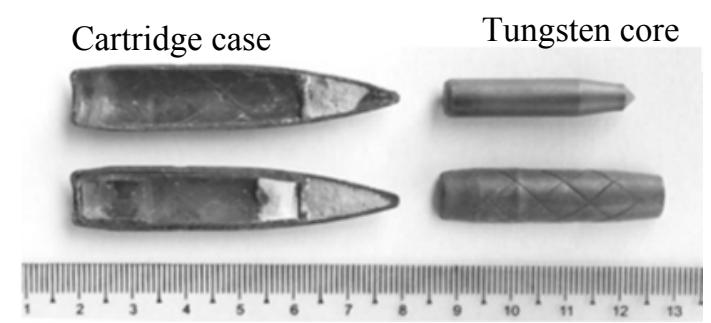

Fig.2 Bullet structure

\subsection{Target.}

The test targets were made of concrete mixed with five kinds of fiber volume fraction $(0 \%, 0.3 \%$, $0.5 \%, 0.7 \%$ and $1.0 \%$ ), and the dimensions is $\Phi 500 \mathrm{~mm} \times 270 \mathrm{~mm}$. The outer periphery of the target was supplied with a $2 \mathrm{~mm}$ steel band for the use as a mold for pouring and restraining the target fragments after striking. Raw materials, mix ratio and preparation process referred to lecture [10], as shown in Table1. The impact speed was controlled at $820 \mathrm{~m} / \mathrm{s}$ in order to focus on the study of the effect of fiber volume fraction. Each fiber volume fraction group consists of two duplicate specimens, with a total number of $5 \times 2=10$.

Table 1. Concrete mix proportion

\begin{tabular}{ccccccccc}
\hline & & \multicolumn{7}{c}{$m / \mathrm{kg} . \mathrm{m}^{-3}$} \\
\cline { 3 - 8 } Code & $V_{f} / \%$ & Water & Cement & Aggregate & Sand & $\begin{array}{c}\text { Tiny silicon } \\
\text { powder }\end{array}$ & $\begin{array}{c}\text { Water } \\
\text { reducer }\end{array}$ & UHMWPE \\
\hline T0 & 0 & 185 & 547 & 936 & 615 & 57.5 & 12 & 0 \\
\hline T3 & 0.3 & 185 & 547 & 936 & 615 & 57.5 & 12 & 2.91 \\
\hline T5 & 0.5 & 185 & 547 & 936 & 615 & 57.5 & 12 & 4.85 \\
\hline T7 & 0.7 & 185 & 547 & 936 & 615 & 57.5 & 12 & 6.79 \\
\hline T10 & 1.0 & 185 & 547 & 936 & 615 & 57.5 & 12 & 9.7 \\
\hline
\end{tabular}

$* V_{f}$ represents the volume fraction of fiber and $m$ represents the mass.

\subsection{Multiple impacts method}

This paper selected three impacts per target as theory of multiple impacts requires the target to suffer more than three shots. As is illustrated in the shooting theory ${ }^{[13]}$, the shooting points will present probability distributions with the area of 4 times the bullets diameter around the aiming point if continuously shooting. But in the experimental condition, there is no bullets scattered problem because it is difficult to achieve continuous random shooting. So in the test, the actual hit point's distribution design is shown in Fig.3. And the targets were shot one by one.

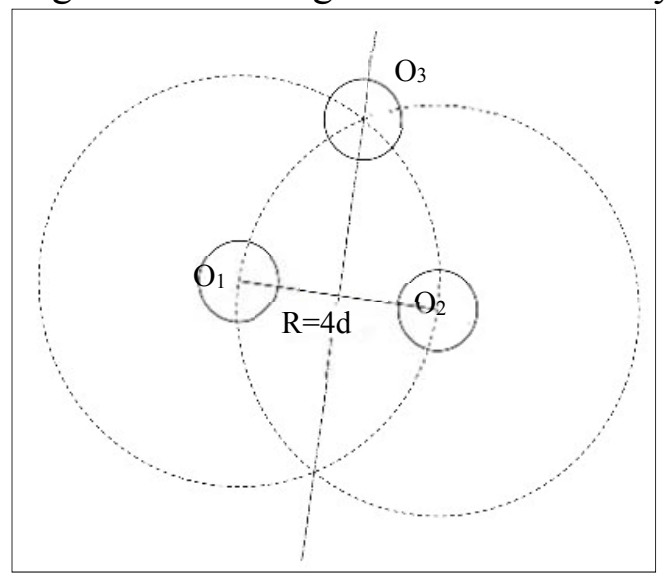

Fig.3 Design of hit point distribution

\section{Results and Analysis}

\subsection{Surface Damage.}

The damage of the targets in the front and back after three shooting impacts was shown in Fig. 4 . 


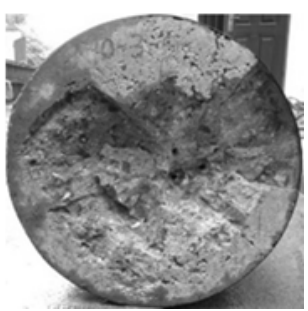

$0 \%$

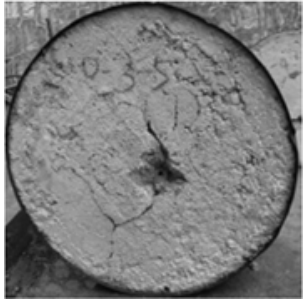

$0 \%$

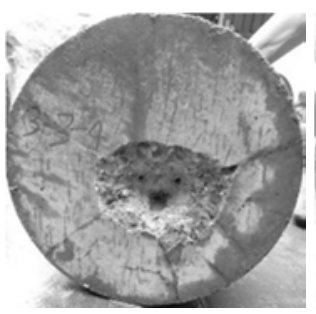

$0.3 \%$

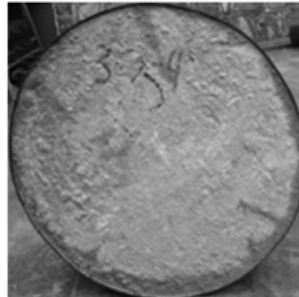

$0.3 \%$

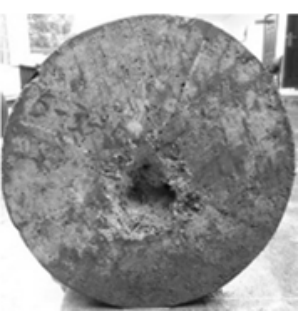

$0.5 \%$

(a) The Front

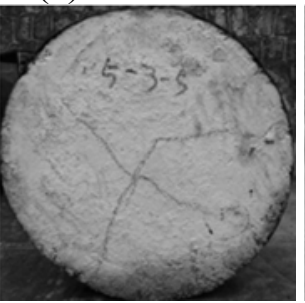

$0.5 \%$

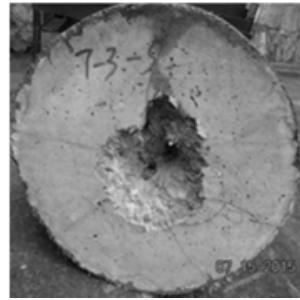

$0.7 \%$

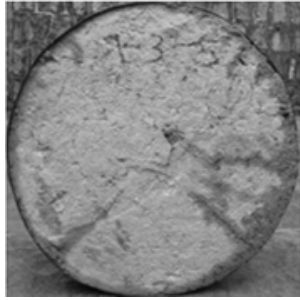

$0.7 \%$

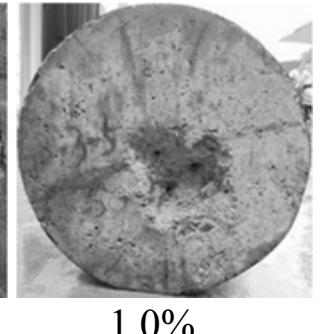

$1.0 \%$

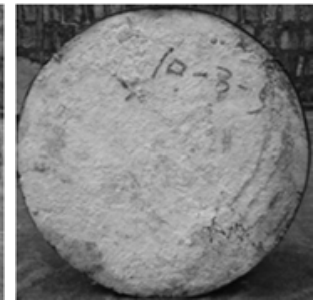

$1.0 \%$

(b) The back

Fig.4 Damage of the target after three impacts

The results showed that the front of the concrete target without UHMWPE fiber had a layered crushing surface as well as a cone-shaped collapsing pit in the back. For the target with $0.3 \%$ UHMWPE volume fraction, the front surface presented an oval funnel pit with a certain size. Besides, there were 5 6 small radial cracks in the front surface and 3 4 in the back surface instead of obvious collapsing damage. Damage of the targets with $0.5 \% \sim 1.0 \%$ UHMWPE volume fraction were nearly the same as $0.3 \%$ except that there was an increase in the size of the oval funnel pit.

\subsection{Inside Damage.}

The profiles of the trajectory were shown in Fig.5 after cutting along the trajectory.

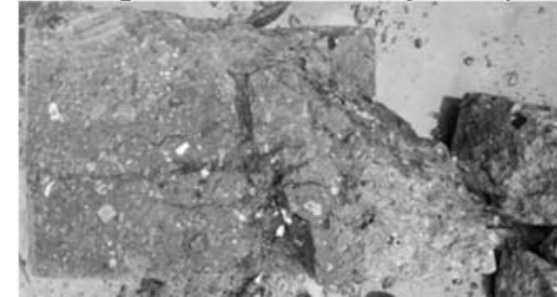

(a) $0 \%$

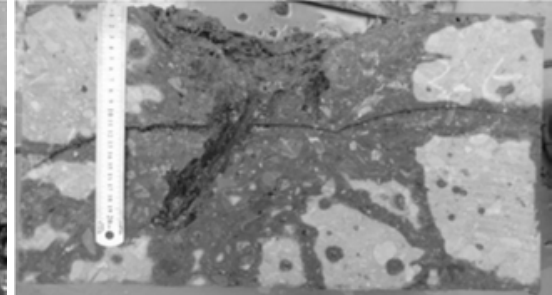

(b) $0.3 \%$

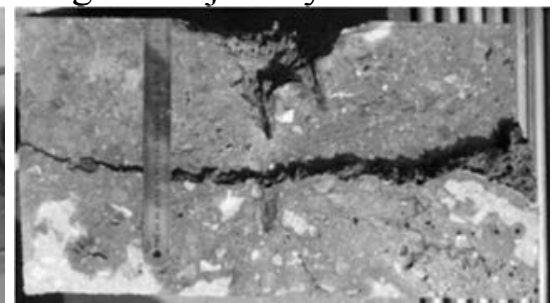

(c) $0.5 \%$

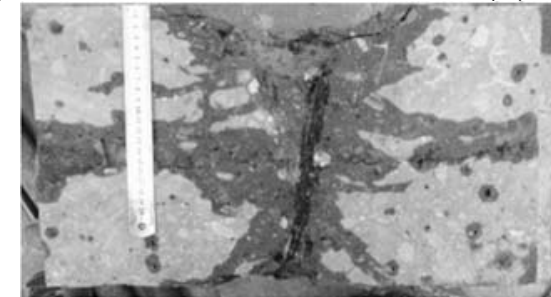

(d) $0.7 \%$

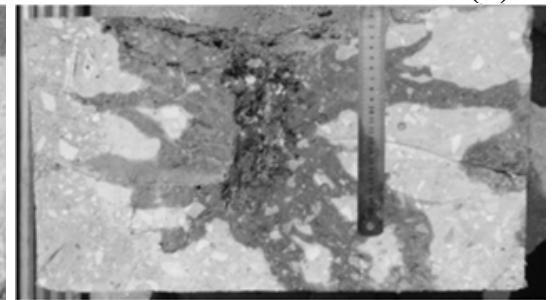

(e) $1.0 \%$

Fig.5 Profiles of the Trajectory

It was showed that there were through cracks from the funnel hole to the target side inside the plain concrete target while fiber-reinforced target still maintained the basic form. Owing to the tensile wave made of the stress wave reflecting on the back, there were several obvious cracks perpendicular to the axis of the plain concrete target. But the other fiber-reinforced target had no obvious cracks except for $0.5 \%$ fiber-reinforced group as its material was possibly not stirred evenly. The addition of UHMWPE fiber improves the ability of concrete to resist fragmentation after multiple impacts, which is consistent with the conclusion of lecture $[10,11,12]$ that the tensile strength of fiberreinforced concrete is obviously increased.

\subsection{Penetration depth analysis.}

The average penetration depth $h$ of each test group after every impact is shown in Table 2, where the penetration depth of the second and third impact had subtracted the depth of the original crater depth. 
Table 2. Penetration depth changed with the number of impact

\begin{tabular}{cccc}
\hline Code & $\mathrm{h} 1 / \mathrm{mm}$ & $\mathrm{h} 2 / \mathrm{mm}$ & $\mathrm{h} 3 / \mathrm{mm}$ \\
\hline T0 & 181.5 & 192.5 & 231 \\
T3 & 170.5 & 176 & 192 \\
T5 & 174 & 178.5 & 196.5 \\
T7 & 178 & 221 & 212 \\
T10 & 178.5 & 225 & 234 \\
\hline
\end{tabular}

It can be found that for the concrete under multiple impacts, the later penetration depth is usually greater than the former, indicating that the former damage to the concrete can reduce its antipenetration ability. The table also shows that there is smaller penetration depth in target with $0.3 \%$ and $0.5 \%$ UHMWPE volume fraction.

The empirical formula of penetration depth applied to semi-infinite targets under multiple impacts was presented by Gomez.J.T [7], which was later improved by the lecture [8 9] as formula (1).

$$
h_{\mathrm{n}}=\frac{2 m}{\pi d_{w}{ }^{2} N \rho_{c}} \ln \left(1+\frac{N \rho_{c} V_{0}^{2}}{S_{n} f_{c}}\right)+4 d
$$

Among formula (1), $m$ is the mess of the Tungsten core, $d_{w}$ is the diameter Tungsten core, $N$ is the shape factor of the bullet, $d$ is the diameter of the total bullet, $V_{0}$ is the speed of impact, $\rho_{c}$ is the density of concrete, $f_{c}$ is the uniaxial compressive strength of concrete, $n$ is the number of impacts, and $S_{n}$ is the strength factor, $h_{\mathrm{n}}$ is the $n$th penetration depth.

$S_{n}$ can be deduced through test value and formula (1). In lecture [8], it is proposed that the strength factor $S_{n}$ under multiple impacts has the relationship with the initial strength factor $S_{1}$ as formula (2).

$$
S_{\mathrm{n}}=S_{1}(\alpha \ln n+1)
$$

$\alpha$ is the parameter to be determined through nonlinear fitting, which reflects the rate at which the anti-impact properties decrease as the number of impacts increase. The data needed and fitted is shown in Table 3.

Tab.3 Basic data and $\alpha$ fitting

\begin{tabular}{cccccccccc}
\hline Code & $\mathrm{m} / \mathrm{g}$ & $d_{w} / \mathrm{mm}$ & $\mathrm{d} / \mathrm{mm}$ & $V_{0} / \mathrm{m} \cdot \mathrm{s}^{-1}$ & $\rho_{c} / \mathrm{kg} \cdot \mathrm{m}^{-3}$ & $f_{c} / \mathrm{MPa}$ & $N$ & $S_{1}$ & $\alpha$ \\
\hline T0 & 19.7 & 7.5 & 12.7 & 820 & 2314 & 53.2 & 0.26 & 17.98 & -0.340 \\
T3 & 19.7 & 7.5 & 12.7 & 820 & 2314 & 52.9 & 0.26 & 20.05 & -0.137 \\
T5 & 19.7 & 7.5 & 12.7 & 820 & 2314 & 47.3 & 0.26 & 21.69 & -0.135 \\
T7 & 19.7 & 7.5 & 12.7 & 820 & 2314 & 49.2 & 0.26 & 20.07 & -0.284 \\
T10 & 19.7 & 7.5 & 12.7 & 820 & 2314 & 50.7 & 0.26 & 19.39 & -0.362
\end{tabular}

It is obvious that the anti-multiple impacts properties of concrete are significantly affected by the UHMWPE fiber volume fraction $V_{f}$, which indicates $S_{1}$ and $\alpha$ also change with it. The relationship among $S_{1}, \alpha$ and $V_{f}$ can be fitted as shown in Fig.6.

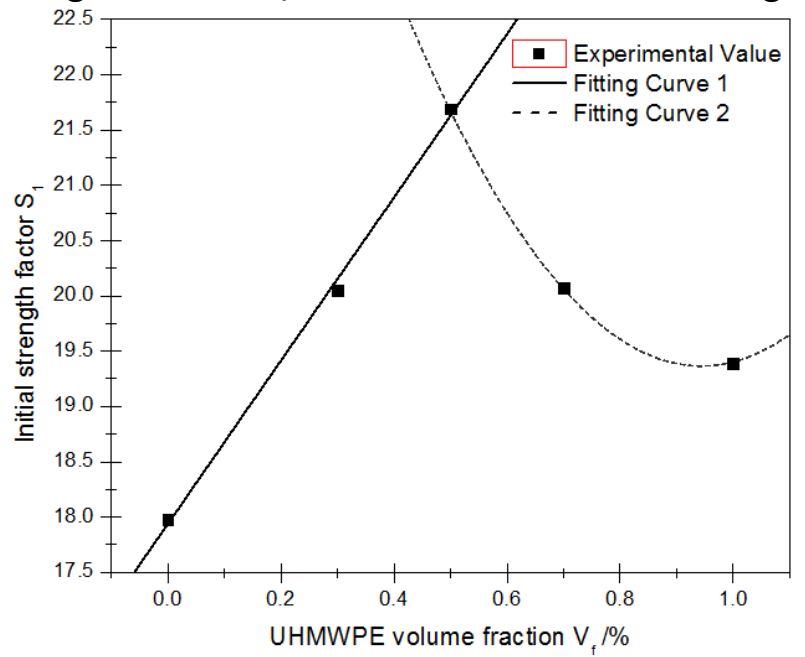

(a) S1 Fitting

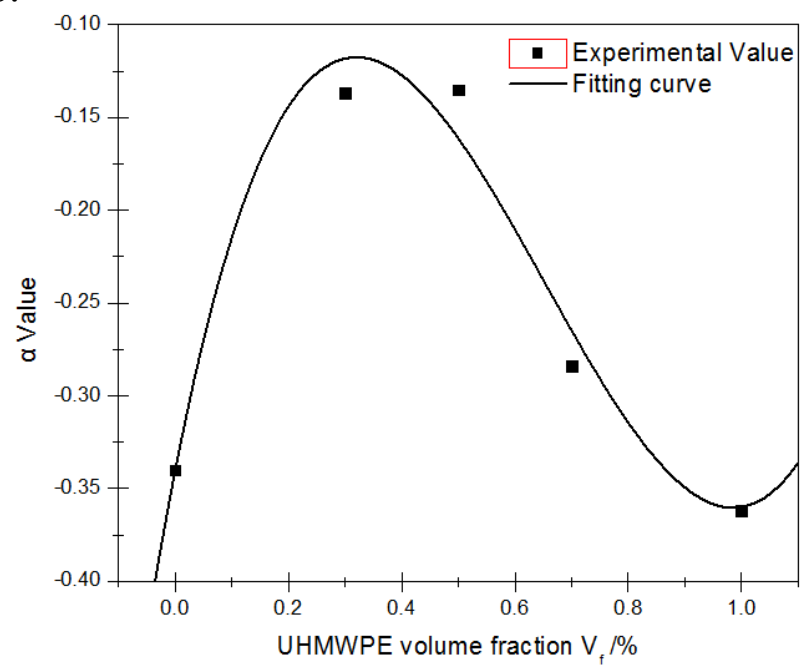

(b) $\alpha$ Fitting

Fig.6 Fitting of S1 and $\alpha$

The fitting results can be shown in formula (3) and (4) $\left(0 \leq V_{f} \leq 1.0\right)$ : 


$$
\begin{aligned}
& S_{1}= \begin{cases}17.94+7.38 V_{f}, & 0 \leq V_{f}<0,5 \\
29.8-22.1 V_{f}+11.7 V_{f}^{2}, & 0.5 \leq V_{f} \leq 1.0\end{cases} \\
& \alpha=1.65 V_{f}^{3}-3.23 V_{f}^{2}+1.56 V_{f}-0.34
\end{aligned}
$$

Combine the formula (1) (4) and the predicted penetration depth can be acquired. The comparison between the calculated value of the penetration depth and experimental value is shown in Fig.7. Though still having some deviation mainly owing to the discrete characteristic of concrete, the formula fitted above can give a basically accurate data within $10 \%$ deviation.

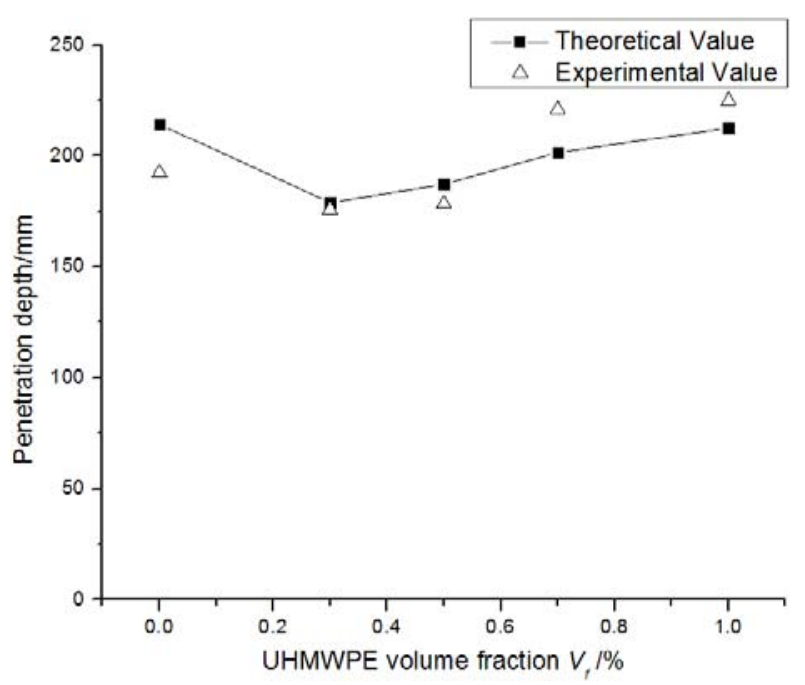

(a) The second impact

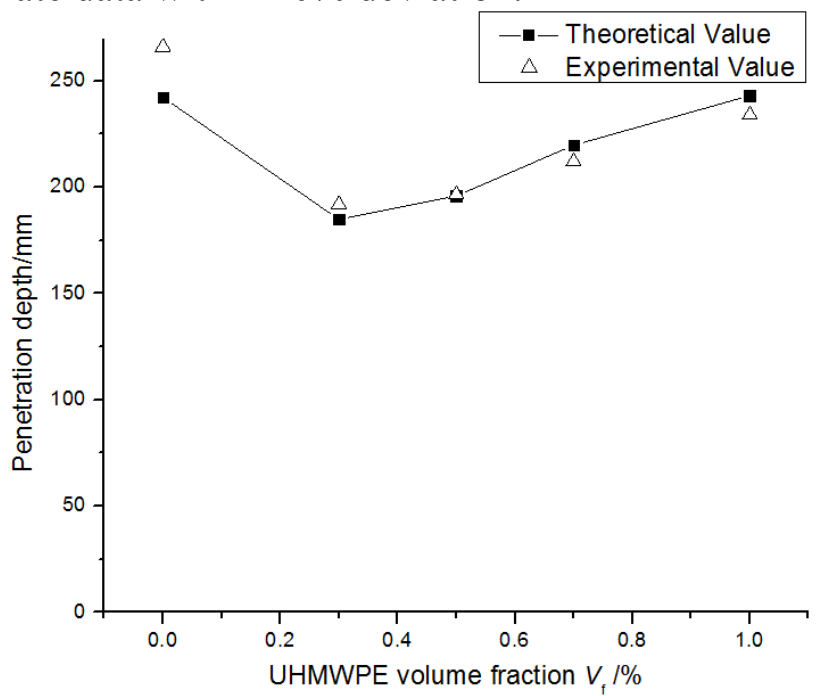

(b) The third impact

Fig.7 Comparison for depth of penetration between theoretical and experimental value

\section{Conclusion}

(a) The performance of plain concrete and UHMWPE fiber reinforced concrete under multiple impacts was studied, including the size of crater, the cracks and the penetration depth. UHMWPE fiber can inhibit the development of cracks in concrete, significantly reducing its surface damage and internal damage under multiple impacts. But there is an optimum value of fiber volume fraction. The reasonable volume fraction of UHMWPE can effectively improve the anti-multiple impacts performance of concrete. For the UHMWPE fiber reinforced concrete studied in this paper, the fiber fraction that has the best performance of anti-multiple impact is between $0.3 \%$ and $0.5 \%$.

(b) The relationship between the strength factor $S_{n}$ and the fiber volume fraction $V_{f}$ was fitted. And the penetration depth predicted by formula (1) suits the experimental data well within a reasonable range of deviation.

\section{References}

[1]. R.Han, S.B.Zhao, F.L.Qu. Experimental study on tensile performance of steel fiber reinforced concrete. China Civil Engineering Journal. Vol. 39 (2006) No.11, p.63-67.

[2]. J.Q.Dong, Y.T.Du, B.L.Wen. Research on mechanical properties and toughening mechanism of basalt fiber reinforced concrete. Industrial Construction. Vol. s1 (2011) p.638-641

[3]. G.A.Pikus. Steel Fiber Concrete Mixture Workability. Procedia Engineering. (2016) No.150, p.2119-2123.

[4]. P.X.Fan, M.Y. Wang, C.M.Song. Anti-strike Capability of Steel-fiber Reactive Powder Concrete. Defence Science Journal. Vol. 63 (2013) No. 4, p.363-368.

[5]. X.N.Zhao, H.E.Yong, X.F.Zhang. Experimental study on penstock penetrating steel fiber reinforced concrete. Journal of Experimental Mechanics. Vol. 26 (2011) No. 2, p. 216-220.

[6]. J.Z.Lai, X.J.Guo, Y.Y.Zhu. Properties of ultra-high performance concrete subjected to penetration and explosion. Journal of Hebei University of Technology. Vol. 6 (2014) No. 3, p. 50-53. 
[7]. Gomez. J. T, Shukla. A. Multiple impact penetration of semi-infinite concrete [J]. International Journal of Impact Engineering. (2001) No. 25, p. 965-979.

[8]. J.Z.Lai, Y.Y.Zhu, S.Xu. Research on anti-multiple penetration performance of ultra-high performance cement-based Composites. Explosion and Shock Waves, Vol. 33 (2013) No.6, p. 601-607.

[9]. Z.G.Jiang, F.Wan, Q.H.Tan. Multi-hit experiments of steel-tube-confined concrete targets. Journal of National University of Defense Technology. Vol. 38 (2016) No. 3, p.:117123.

[10]. L.H.Yan, Y.W.Zhang, L.Zhu. Basic mechanical properties of ultra-high molecular weight polyethylene fiber concrete. Journal of National University of Defense Technology. (2014) No.6, p. 43-47.

[11]. L.F.Li, L.H.Yan, Y.W.Zhang. Experiment Research of UHMWPE Fiber Reinforced Concrete under Triaxial Compression. International Conference on Applied Science \& Engineering Innovation. WuHan 2015, p.112-117.

[12]. Y.W.Zhang, L.H.Yan, L.Zhu. Experiment research on mechanical properties and penetration performance of UHMWPE fiber concrete. Advanced Materials Research. (2014), p.989-994.

[13]. W.R.Li. Shooting principle of infantry weapon. Ordnance Industry Press. Institute of Weapons and Trade (No.208), 1987, p.112-114. 